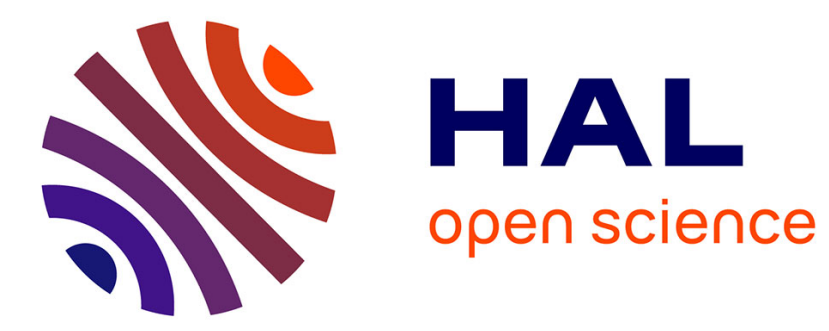

\title{
Photon beat study of internal modes in large polymer coils
}

\author{
M. Adam, M. Delsanti
}

\section{To cite this version:}

M. Adam, M. Delsanti. Photon beat study of internal modes in large polymer coils. Journal de Physique Lettres, 1977, 38 (13), pp.271-273. 10.1051/jphyslet:019770038013027100 . jpa-00231375

\section{HAL Id: jpa-00231375 https://hal.science/jpa-00231375}

Submitted on 1 Jan 1977

HAL is a multi-disciplinary open access archive for the deposit and dissemination of scientific research documents, whether they are published or not. The documents may come from teaching and research institutions in France or abroad, or from public or private research centers.
L'archive ouverte pluridisciplinaire HAL, est destinée au dépôt et à la diffusion de documents scientifiques de niveau recherche, publiés ou non, émanant des établissements d'enseignement et de recherche français ou étrangers, des laboratoires publics ou privés. 


\title{
PHOTON BEAT STUDY OF INTERNAL MODES IN LARGE POLYMER COILS
}

\author{
M. ADAM and M. DELSANTI \\ DPh-G/PSRM, C.E.N. Saclay, B.P. 2, 91190 Gif sur Yvette, France
}

(Reçu le 4 avril 1977, révisé le 3 juin 1977, accepté le 7 juin 1977)

\begin{abstract}
Résumé. - Nous étudions la lumière diffusée quasi-élastiquement par des solutions diluées de polystyrène, de masses moléculaires élevées $\left(M_{\mathrm{w}}=8,4 \times 10^{6}\right.$ et $\left.M_{\mathrm{w}}=24 \times 10^{6}\right)$ en bon solvant (benzène).

Le produit du rayon de gyration $R$ par le vecteur de diffusion $k$ varie entre 0 et 13,8 . Nous observons deux régimes distincts :

a) à $k R \leqslant 1$ le profil du spectre de la lumière diffusée est une fonction exponentielle dont le temps de relaxation $1 / \tau_{k}=D k^{2}$,

b) à $k R>4$ la décroissance n'est plus exponentielle et $1 / \tau_{k} \propto k^{x}$ où $x=2,85 \pm 0,05$.

Le profil observé dans le domaine $k R<4$ est en parfait accord avec le profil calculé par E. DuboisViolette et P. G. de Gennes en 1967 [1].
\end{abstract}
Abstract. - We have measured the inelastic scattering of light by dilute polystyrene coils (mole- cular Weight $M_{\mathrm{w}}=8.4 \times 10^{6}$ and $M_{\mathrm{w}}=24 \times 10^{6}$ ) in a good solvent (Benzene).
The product of the radius of gyration $R$ multiplied by scattering wave vector $k$ ranges from 0 to 13.8. We find two regimes :
a) for $k R \leqslant 1$ a simple exponential decay with relaxation rate $1 / \tau_{k}=D k^{2}$,
b) for $k R>4$ a non-exponential decay with $1 / \tau_{k} \propto k^{x}$ where $x=2.85 \pm 0.05$.
The precise shape of the non-exponential decay agrees surprisingly well with a 1967 calculation by E. Dubois-Violette and P. G. de Gennes [1].

1. Introduction. - Inelastic light scattering by separate polymer coils in solution has been actively studied [2-3]. However most data have been taken on rather small coils, which act as point scatterers performing a Brownian motion. This essentially measures the corresponding diffusion coefficient $D_{0}$. In the present note, we discuss data taken on polymer coils of very large mass. We have used two samples :

- sample $\mathrm{I}\left(M_{\mathrm{w}}=8.4 \times 10^{6}\right)$ contains coils of gyration radius $\left({ }^{1}\right) R=1900 \AA$,

- sample II has $\left(M_{\mathrm{w}}=24 \times 10^{6}\right)$ and $R=3600 \AA$.

The molecular weights check well with our own measurements of $D_{c}\left({ }^{2}\right)$ [3] and this suggests that polydispersity effects - although surely present are not dramatic.

${ }^{(1)}$ These values of $R$ were deduced from conventional light scattering experiments [4].

$\left(^{2}\right)$ Our value of $D_{\mathrm{c}}$ for sample $I\left(C=8.4 \times 10^{-4} \mathrm{~g} / \mathrm{cm}^{3}\right)$ is (5.5 \pm 0.4$) 10^{-8} \mathrm{~cm}^{2} / \mathrm{s}$ the value which would be obtained from extrapolation of our data at lower $M$ up to $M_{\mathrm{w}}=8.4 \times 10^{6}$ and $C=8.4 \times 10^{-4} \mathrm{~g} / \mathrm{cm}^{3}$ is $D_{\text {ext }}=5.7 \times 10^{-8} \mathrm{~cm}^{2} / \mathrm{s}$.
In the present note, we are concerned mainly with the inelastic scattering measured at high wave vector. With our largest mass (sample II) we can reach values of $k R \sim 14$, and we can really probe the internal properties of the chain (in addition, a nice feature of this limit is that polydispersity becomes unimportant).

RESULTS. - For a given $k$ vector we measure directly the time-dependent correlation function

$$
S(k, t)=\left\langle\delta C_{-k}(0) \delta C_{k}(t)\right\rangle
$$

where $\delta C_{k}$ is one Fourier component of the concentration fluctuation $\left({ }^{3}\right)$. This function decreases with time with a characteristic decay time $\tau_{k}$.

Figure 1 gives the measured ratio $1 / \tau_{k}$ in a dimensionless form : we divide $1 / \tau_{k}$ by its low $k$, low $C$ limit, i.e. $D_{0} k^{2}$ and plot the results as a function of $k R$. Values for various concentrations are given.

$\left({ }^{3}\right)$ Our heterodyne photon beating spectrometer is described in reference [5-6]. 


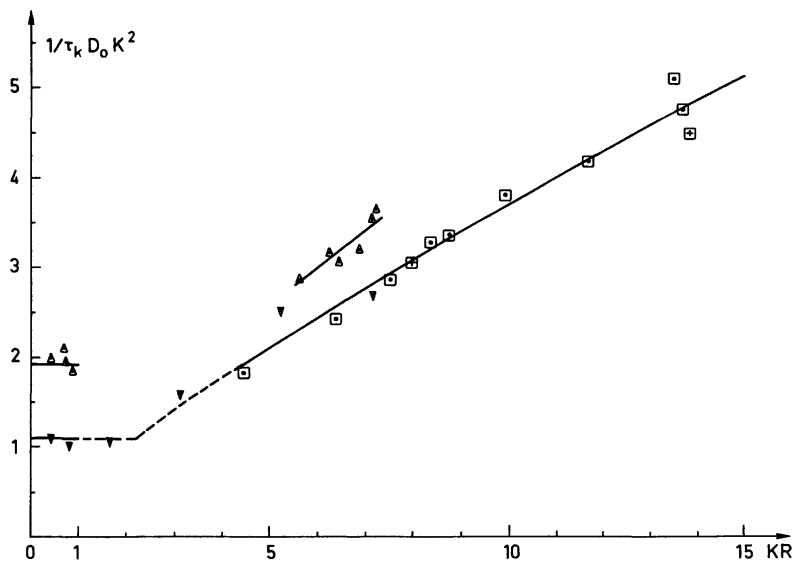

FIG. 1. - Variation of the ratio $\frac{1}{\tau_{k}} \mid D_{0} k^{2}$ as a function of $k R$ for various concentrations

$$
\begin{array}{ll}
\triangle C=8.4 \times 10^{-4} \mathrm{~g} / \mathrm{cm}^{3} & M_{\mathrm{w}}=8.4 \times 10^{6} \\
\nabla C=8.6 \times 10^{-5} \mathrm{~g} / \mathrm{cm}^{3} & \\
\square C=4.9 \times 10^{-4} \mathrm{~g} / \mathrm{cm}^{3} & M_{\mathrm{w}}=24 \times 10^{6} . \\
\boxplus C=1.5 \times 10^{-4} \mathrm{~g} / \mathrm{cm}^{3} &
\end{array}
$$

1) The low concentration limit of $1 / \tau_{k}$ is welldefined. In particular at high $k R$ the results are very insensitive to $C$.

2) The $C \rightarrow 0$ curve is the same for the two samples, i.e. is independent of the molecular weight. It shows two regions :

a) For $k R<1,1 / \tau_{k}=D_{0} k^{2}$ (simple diffusion). In this limit $S(k, t)$ is a simple exponential.

b) For $k R \geqslant 4,1 / \tau_{k}$ increases faster that $k^{2}$. We are seeing the internal modes of the chain. Here the decay of $S(k, t)$ is not exponential.

We conclude that the relaxation rate has a scaling form

$$
\frac{1}{\tau_{k}}=D_{0} k^{2} \cdot f(k R)
$$

where $f(k R)=1$ for $k R<1$, and $f(k R)=(k R)^{u}$ for $k R \geqslant 4$ with an exponent $u=0.85 \pm 0.05$.

Our best determination of $u$ comes from a detailed study of the high $k R$ limit, where some theoretical predictions have been quoted :

a) A calculation by E. Dubois-Violette and P. G. de Gennes including backflow effects but assuming an ideal chain as regards the elastic forces [1].

b) A mode-mode coupling approach by $\mathbf{R}$. Kapral et al. with the same assumptions but a different calculational scheme [7].

In reference [7] it is postulated that $S(k, t)$ is exponential in time, but our data rule out this possibility. In fact, we find that our $S(k, t)$ can be described surprisingly well by the analytic form described in reference [1] namely

$$
\begin{aligned}
& \frac{S(k, t)}{S(k, 0)}= \\
& =\left\{\begin{array}{rr}
\left(t \tau^{-1}(k)\right)^{2 / 3} \int_{0}^{\infty} \mathrm{d} u \exp \left[-\left(t \tau^{-1}(k)\right)^{2 / 3} u(1+h(u))\right] \\
1 & \text { When } t \neq 0
\end{array}\right. \\
& \text { When } t=0
\end{aligned}
$$

with

$$
h(u)=\frac{4}{\pi} \int_{0}^{\infty} \frac{\mathrm{d} y \cos y^{2}}{y^{3}}\left[1-\exp \left(-y^{3} u^{-3 / 2}\right)\right] .
$$

The characteristic frequency

$$
\tau^{-1}(k)=\frac{1}{2^{3 / 2} 3 \pi} \frac{k_{\mathrm{B}} T}{\eta_{0}} k^{3}
$$

depends only on the solvent viscosity $\eta_{0}$ and the temperature $T$.

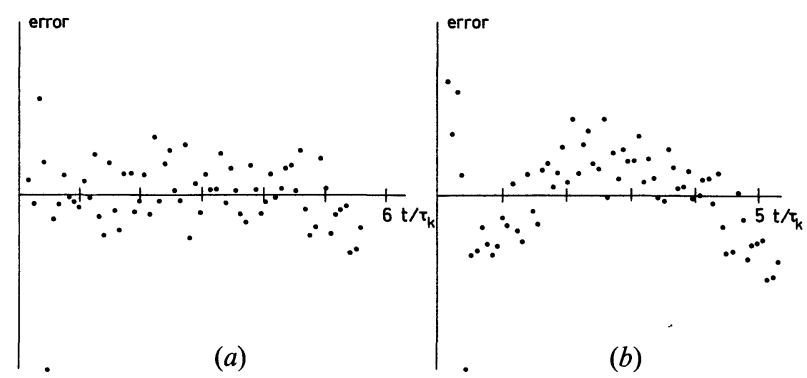

Fig. 2. - At large angles, the experimental curves, obtained on both samples for values of the $k$ vector such as $k R \geqslant 4.4$, are fitted to the theoretical function defined by eq. (2), the numerical values of which have been calculated point by point and then linearly interpolated. Figure 2 represents the curve of error obtained when the experimental curve is fitted to eq. (2) (Fig. 2a) or to an exponential (Fig. 2b).

The extent of the agreement is shown in figures $2 a, b$; the quality factors for the fit to eq. (2) are listed in table I.

In our detailed assessment of the exponent $u$, we thus used as the definition of $\tau_{k}$ the time obtained from a fit with eq. (2). Because the fit is excellent, and the data $\tau_{k}$ are here insensitive to $C$ and to $M$ the accuracy is rather high.

Our data give $1 / \tau_{k} \propto k^{u+2}$ and $u+2=2.85 \pm 0.05$, figure 3. Both references $[a]$ and $[b]$ predict $1 / \tau_{k} \propto k^{3}$ for $k R \gg 1$.

A more recent discussion, based on scaling concepts, suggests that the result is more general [8] : if the coil behaves like a stokes sphere of hydrodynamic radius $\gamma R$ (where $\gamma$ is a constant number) we expect to have

$$
D_{0}=\frac{k T}{6 \pi \gamma \eta_{0} R}
$$

( $\eta_{0}$ is the solvent viscosity). 


\section{TABLE I}

Some data obtained at high $k R$ values : $V$ is the relative standard deviation of $\tau_{k}, Q$ represents the quality factor, defined by

$$
Q=1-\frac{\sum_{i=1}^{N-1} \varepsilon_{i} \varepsilon_{i+1}}{\sum_{1}^{N} \varepsilon_{i}^{2}}
$$

where $N$ is the number of experimental points, $\varepsilon_{i}$ the deviation of the $i$-th experimental from the $i$-th theoretical point.

\begin{tabular}{|c|c|c|c|c|}
\hline & $M_{\mathrm{w}}=24 \times 10^{6}$, & $C=4.9 \times$ & $\mathrm{g} / \mathrm{cm}^{3}$ & \\
\hline$k R$ & $k \times 10^{-5}\left(\mathrm{~cm}^{-1}\right)$ & $\tau^{-1} \times\left(s^{-1}\right)$ & $V \times 10^{2}$ & $Q$ \\
\hline- & - & - & - & - \\
\hline 13.7 & 3.828 & $1.35 \times 10^{4}$ & 1.4 & 0.86 \\
\hline 13.5 & 3.773 & $1.29 \times 10^{4}$ & 1.3 & 1 \\
\hline 11.5 & 3.263 & $8.47 \times 10^{3}$ & 2.5 & 0.9 \\
\hline 9.9 & 2.767 & $5.21 \times 10^{3}$ & 2 & 0.84 \\
\hline 8.7 & 2.446 & $3.69 \times 10^{3}$ & 1.5 & 0.93 \\
\hline 8.3 & 2.339 & $3.42 \times 10^{3}$ & 1.1 & 0.92 \\
\hline 7.5 & 2.095 & $2.40 \times 10^{3}$ & 1.3 & 0.88 \\
\hline 6.3 & 1.780 & $1.42 \times 10^{3}$ & 1.5 & 0.79 \\
\hline 4.4 & 1.241 & $5.32 \times 10^{2}$ & 1.5 & 0.82 \\
\hline
\end{tabular}

We insert this into eq. (1) and consider the high $k R$ limit, then $1 / \tau_{k}$ must probe inner modes of the coil, and must be independent of the overall coil size. This requires $f(k R)$ to be linear in $k R$.

There is a rather striking similarity between our results and the studies on light scattering by critical binary mixtures [9]. In both cases there is a relaxation rate $1 / \tau_{k}$ dependent on $k$ with a $k^{2}$ behaviour at low $k L$ ( $L=R$ in the macromolecule system, $L$ is the correlation length in the critical case) and a behaviour very near to $k^{3}$ at high $k L$. The deviations from $k^{3}$ are known to be meaningful and to represent a slight anomaly in the viscosity near the critical point [10]. It is not clear whether our measured difference between 2.85 and 3 can be interpreted in a similar way.

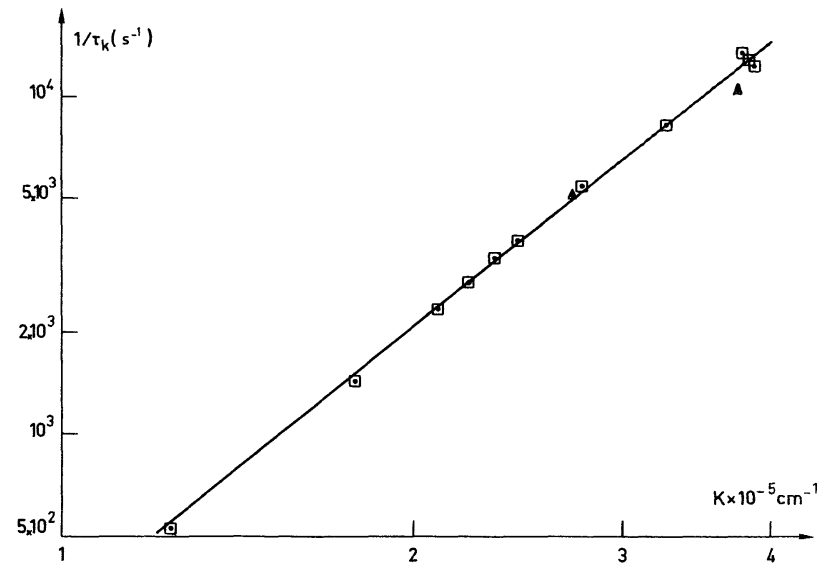

FIG. 3. - Log-log plot of the inverse of the characteristic decay time as a function of the transfer vector $k$ at high $k R$ values $(k R \geqslant 4.4)$ and $C \rightarrow 0$. $M_{\mathrm{w}}=24 \times 10^{6} . \triangle M_{\mathrm{w}}=8.4 \times 10^{6}$.

We end up with one technical remark: the E. Dubois-Violette, P. G. de Gennes calculation, at high $k R$, was written for infinite chains. At first sight one might think that for finite chain one should add to $1 / \tau_{k}$ a contribution due to the uniform translation of the overall coil $\left(D_{0} k^{2}\right)$, and this correction could be significant in some of our cases (when $1 / \tau_{k}$ ard $h_{0} k^{2}$ have the same order of magnitude). In fact, in references [7] and [8], the inverse of the rela . time $1 / \tau_{k}$ is interpreted as the product $D(k) \Omega^{2},{ }^{w / h e r e ~} D(k)$ is a $k$-dependent diffusion coefficient of rabinit of size $k^{-1}$ [11].

To summarize, we have been able wo study the internal motions of a single coil. We find that the characteristic relaxation rates obey a scaling law and that their dependence on wave vector is not very far from the predictions of the simplest dynamic scaling model.

Acknowledgments. - We thank P. G. de Gennes, G. Jannink, J. des Cloizeaux, P. Pincus, F. I. B. Williams for helpful discussions and E. Dubois-Violette for communicating the numerical data of the function $S(k, t) / S(k, 0)$.

\section{References}

[1] Dubois-Violette, E. and De Gennes, P. G., Physics 3 (1967) 181.

[2] Wu Nan Huang and Frederick, J. E., J. Chem. Phys. 58 (1973) 4022.

WU NAN HuANG and Frederick, J. E., Macromolecules 7 (1974) 34.

King, T. A., Knox, A. and Mc Adam. J. D. G., Chem. Phys. Lett. 19 (1973) 351.

Saleh, B. E. A. and Hendrix, J., J. Chem. Phys. 12 (1976) 25. Mc Adam, J. D. G. and King, T. A., Chem. Phys. Lett. 28 (1974) 90.

Mc Adam, J. D. G. and King, T. A., Chem. Phys. 6 (1974) 109.

[3] Adam, M., Delsanti, M., J. Physique 37 (1976) 1045.
[4] Decker, D., Thesis Strasbourg (1968).

[5] Adam, M., Hamelin, A. and Bergé, P., Opt. Acta 16(1969) 337.

[6] AdAM, M., DelsantI, M. to appear in Macromolecules.

[7] Kapral, R., Ng, D. and Whittington, S. G., J. Chem. Phys. 64 (1976) 539.

[8] De Gennes, P. G., Macromolecules 9 (1976) 587.

[9] Bergé, P., Calmettes, P., LaJ, C. and Volochine, B., Phys. Rev. Lett. 23 (1969) 693.

Swinney, L. and Henry, D. L., Phys. Rev. A 8 (1973) 2586.

[10] Calmettes, $P$. to be published.

[11] Brochard, F. and DE Gennes, P. G. to appear in J. Chem. Phys. 